\title{
Radiology of the adrenal incidentalomas. Review of the literature
}

\author{
Farrugia FA, Martikos G, Surgeon C, Tzanetis P, Misiakos E, Zavras N, Charalampopoulos A \\ Third Department of Surgery, University of Athens, ATTIKON Hospital, Athens, Greece \\ E-mail:farrugiafa@gmail.com
}

\begin{abstract}
The term "adrenal incidentaloma" is a radiological term. Adrenal incidentalomas are adrenal tumors discovered in an imaging study that has been obtained for indications exclusive to adrenal conditions (Udelsman 2001; Linos 2003; Bulow et al. 2006; Anagnostis et al. 2009). This definition excludes patients undergoing imaging testing as part of staging and work-up for cancer (Grumbach et al. 2003; Anagnostis et al. 2009). Papierska et al. (2013) have added the prerequisite that the size of a tumor must be "greater than $1 \mathrm{~cm}$ in diameter", in order to be called incidentaloma. Although in the most cases these masses are non-hypersecreting and benign, they still represent an important clinical concern because of the risk of malignancy or hormone hyperfunction (Barzon et al. 2003). The adrenal tumors belong to the commonest incidental findings having been discovered (Kanagarajah et al. 2012).
\end{abstract}

Key words: adrenal incidentaloma, radiology, ultrasound, computer tomography, magnatic resonance, functional imaging

The adrenal incidentaloma (AI) is a term that may be applied to various diseases sharing the same way of (incidental) radiological discovery. Because of the great heterogeneity, it has been called a modern technology disease (Chidiac and Aron 1997), which is actually a cluster of diseases (Angeli and Terzolo 2002).

A large study on AI has been conducted in Italy by Mantero et al. (2000). The aim of their study was to perform a national survey on AI. They have retained for the final analysis, 1004 cases, from which 380 patients were operated (38\%). The majority of the operated cases were $52 \%$ adenomas, $12 \%$ adrenomal carcinoma (ACC), $11 \%$ pheochromocytomas, $5 \%$ cystic lesions, $4 \%$ ganglioneuromas, $2 \%$ metastases and $6 \%$ other histological diagnoses (Mantero et al. 2000).

In the above-mentioned survey, it has been reported that the reasons for an abdominal imaging procedure were (non) "aspecific" symptoms (36\%); abdominal pain (36\%), including either an ill-defined discomfort or biliary and renal colic; postsurgery follow-up (8\%); acute abdomen (1.5\%); abdominal trau- ma (1.5\%); and other (17\%). No significant difference in the gender indications was apparent (Mantero et al. 2000).

The adrenal masses have been detected by abdominal ultrasound in 631 cases (71\%), computer tomography (CT) in 247 (28\%), and magnetic resonance imaging (MRI) in 9 (1\%) (Mantero et al. 2000). In addition, this study has shown that abdominal U/S detected more often right-sided than left-sided tumors (65\% vs. 26\%), whereas CT detected them at similar rates ( $43 \%$ vs. $43 \%$ ). They have concluded that abdominal U/S might be able to visualize the right adrenal gland better than the left one (Mantero et al. 2000).

Despite the fact that this study was done in the year 2000, somebody may think that it is outdated and may be misleading in this era of high resolution cross sectional imagining by CT and MRI. It is the largest study of this kind in the literature and it is still cited in almost all the studies regarding the AI. Besides, not all the hospitals around the world have 
the most recent imaging modalities. This study is the only study that describes the full epidemiological characteristics of the presentation of the AI. The majority of the studies after 2000 are restricted to the incidence of AI in CT or MRI or both (Blake et al. 2010; Boland et al. 2008; Jain 2013; Kim et al. 2013; Herr et al. 2014; Paterson et al. 2014).

The fact that ultrasound have been more frequently used, may be surprising, but the same has been found in the recent studies of Paprieska et al. (2013) and Tabuchi et al. (2015).

Location: In recent studies, AI was more frequently localized on the left than the right side (Cho et al. 2013; Kim et al. 2013; Tabuchi et al. 2015). Bilateral masses have been observed from 9.4-20\% (Kasperlik-Zaluska et al. 2010; Tabuchi et al. 2015). Bilateral incidentalomas are more likely associated with subclinical Cushing syndrome and less likely with the pheochromocytoma (Pasternak et al. 2015). The average diameter of tumors was $21 \pm 11 \mathrm{~mm}$ (Paterson et al. 2014; Tabuchi et al. 2015).

\section{Material and Methods}

We conducted an internet search using the reference software "ENDNOTE version 7" (2003) and connected by the help of the "connect" command with "Pub-Med" and used the search terms "Adrenal" and "Incidentaloma", and "Radiology" and "Imaging" without any time limit. We gathered 662 studies, the oldest with the term "Adrenal Incidentaloma" was from 1982. From the literature, we kept only the studies of AI that were relevant with the radiology of AI. The aim of the study was to present the radiological characteristics of AI, having in mind the surgeons rather than the radiologists.

Prevalence. Improvements in abdominal imaging techniques and technologies have resulted in the detection of an increasing number of AIs (NIH 2002).

The prevalence of adrenal incidentalomas varies in the different autopic studies, depending on the age of the patient and the size of the tumor. The mean prevalence in a total of 71206 cases from the literature is $2.3 \%$, ranging from 1 to $8.7 \%$, without significant differences between females and males (Barzon et al. 2003). These masses are associated with changes taking place in the organ in the course of a physiological process of aging (Dobbie 1969; Hornsby 2002). The prevalence of AI varies with age. The prevalence of AI detected in autopsy is less than $1 \%$ for ages younger than 30 years and increases to $7 \%$ in those having 70 years of age or older (Barzon et al. 2003; Zeiger et al. 2011; Papierska et al. 2013).
Causes of adrenal mases (Conder et al. 2009).

A. Functional: Adenoma causing Conn's or Cushing's syndrome; Pheochromocytoma; Aldosteronoma; Adrenal carcinoma;

B. Malignant: Metastases; Carcinoma; Lymphoma; Neuroblastoma;

C. Benign: Non-functioning adenoma; Angiomyolipoma; Cysts; Hemorrhage.

Radiology of adrenal diseases:

An introduction about adrenal radiology. Adrenal lesions can be categorized as primary or metastatic, benign or malignant, and functioning or nonfunctioning ones (Young 2007; Boland et al. 2008). The primary goal of imaging is to distinguish among adrenal adenoma, adrenal carcinoma, pheochromocytoma, and metastatic lesions (Zeiger et al. 2009).

The strength and practicality of any imaging test devised to differentiate these lesions will ultimately depend on the test sensitivity and specificity (Boland et al. 2008). First, the test needs to be sufficiently sensitive to detect focal adrenal lesions when present. However, while high sensitivity is useful, the critical characteristic of an imaging test is its ability to characterize the adrenal lesions, i.e. to distinguish those that require further evaluation from those that can be safely left alone (Boland et al. 2008). High-test specificity is, therefore the crux of adrenal imaging, and tests must be devised that are as close to $100 \%$ specific as possible (Boland et al. 1998).

Despite the fact that adrenals can be a site of metastasis from other organs, there are, unfortunately, no recommendations about concurrent radiological studies in other organs, which may be the site of a primary cancer likely to metastise in adrenals - like for example, lungs (Chest X Ray) in the work-up of AI in all the studies that we had studied.

Ultrasound (U/S). As it has been reported in an Italian study (Mantero et al. 2000), 71\% of AI are first discovered by the ultrasonography. This has been also reiterated by other studies mentioned above. The normal adrenal gland that is $3-6 \mathrm{~mm}$ thick and adrenal masses as small as $1.3 \mathrm{~cm}$ can be delineated (Yeh 1980).

Although the frequency of visualizing normal adrenal glands $(78.5 \%$ on the right and $44 \%$ on the left) with sonography is not as high as with CT scan, masses are more readily detected than the normal glands (Yeh 1980). Their physiological thickness does not exceed $12 \mathrm{~mm}$, while the sensitivity of this method is over $90 \%$ for diagnosing tumors $2 \mathrm{~cm}$ in size (Trojan et al. 2002).

When a suprarenal mass is demonstrated by ultrasound, it is necessary to establish whether it is of an adrenal or renal origin. If between the kidney and 
the mass a margin can be demonstrated, the origin is most likely adrenal. In masses of renal origin, a margin should not be evident. Delineation of this margin can be readily accomplished by gray scale technique. It is somewhat more difficult to accomplish this with bistable scans (Forsythe et al. 1977).

Before the development of modern cross-sectional imaging techniques, tumors were characterized based on their vascularity as shown by angiography (Ghiatas et al. 1996). Neoplastic vessels give high frequency signals due to high velocity flow resulting from their low resistance, due to lack of smooth muscle in the wall of the vessels and the arteriovenous anastomoses (Taylor et al. 1988).

Ghiatas et al. (1996) have studied 47 patients to find out whether it is possible to use "the flow imaging in the differential diagnosis of adrenal masses". They have concluded that "Doppler ultrasound and power imaging do not help in the differentiation of benign from malignant adrenal masses" (Ghiatas et al. 1996). Among tumors, often lymphoma and endocrine tumors (pheochromocytoma) are hypervascularized (Nurnberg et al. 2011).

Contrast enhanced ultrasound gave promising results in a few studies (Slonina et al. 2006; FriedrichRust et al. 2008; Nurnberg et al. 2011).

Another modality of ultrasound is CEUS (Contrast enhanced ultrasound). Lipoma and myelolipoma regularly do not show a wash out effect. Malignant tumors do not show a characteristic phenomenon, both wash out and late contrast accumulation occurs. The contrast media performance is inhomogeneous, e.g. also adenomas show a wash out phenomenon.

Ultrasound elastography and Endoscopic ultrasound (EUS) with SSWE (supersonic shear wave elastography) are new promising techniques for the evaluation of the adrenal masses (Saftoiu and Vilma 2006; Stapa et al. 2014). Endoscopic ultrasound (EUS) with SSWE is a feasible technique that can be applied during ultrasound of the abdomen and retroperitoneum and it is a promising method for the evaluation of left adrenal gland masses and presents potential for the differentiation of solid and cystic adrenal lesions (Saftoiu and Vilma 2006; Stapa et al. 2014). As a general rule, malignant masses tend to be harder (blue). No consistent elastography criteria have been proposed so far (Popescu and Saftoiu 2014).

Today, even after numerous studies, it is impossible to distinguish exactly between the benign (adenoma) and malignant tumors (metastasis) without histology or cytology (Nurnberg et al. 2011).

Computer tomography (CT). The AIs are detected by CT scan at about 28\% (Mantero et al. 2000). CT is the primary diagnostic imaging modality for the evaluation of the adrenal disorders (Karstaedt et al. 1978; Montagne et al. 1978; Wilms et al. 1979; Abrams et al. 1982). On the pre-contrast CT, the adrenals have a soft tissue density similar to that of the liver (Lee 1998). The adrenal cortex and medulla cannot be reliably distinguished by either CT or MRI (Karstaedt et al. 1978; Montagne et al. 1978). Although, no strict measurements have been standardized, any area thicker than $10 \mathrm{~mm}$ is probably abnormal (Lee 1998). It must be recognized that in the face of stress (as may be seen in severely ill patients), the adrenals may become enlarged in response to physiologically high circulating adrenocorticotropic hormone (ACTH) levels (Boland et al. 2008).

When optimal CT scanning technique is used, normal or pathologic adrenal glands can be well visualized in virtually in $100 \%$ of patients (Lee 1998). Large and small masses and hyperplasia can be readily detected when present (Lee 1998). With proper technique, masses smaller than $5 \mathrm{~mm}$ can be detected (Korobkin et al. 1979; Eghrari et al. 1980; Abrams et al. 1982). The accuracy of CT for diagnosis of adrenal masses has been reported as being better than $90 \%$ (Lee 1998) and a normal appearance of the adrenal effectively excludes the presence of an adrenal tumor (Lee 1998). Because many small adrenal masses are isodence with adrenal tissue, they are detected as focal bulges on the otherwise smooth adrenal surface. Focal enlargement is a more important finding than any measurement (NIH 2002).

According to the NIH Statement (2002), the size and appearance of an adrenal mass on CT or MRI may help distinguish between benign and malignant lesions. The available data suggest that nearly all lesions smaller than $4 \mathrm{~cm}$ are benign. They use the words "may" and "suggest", meaning that we are not $100 \%$ sure from CT and MRI about the nature of the tumor neither from its size, nor from its appearance. One has to keep in mind that all the adrenocortical carcinomas (ACC) before they become more that 4 $\mathrm{cm}$ they were $0.5,1,1.5,2,3,3.5 \mathrm{~cm}$.

The evaluation of radiation attenuation coefficient, i.e. the so-called density, is the most important element of CT scan description of an adrenal tumor. Density is expressed in Hounsfield Units (HU) and represents the value of X-radiation attenuation linear coefficient for the examined tissue in comparison with the coefficient measured for water. The range is $2000 \mathrm{HU}$ : the coefficient for water is $0 \mathrm{HU}$, for air (-) $1000 \mathrm{HU}$, for adipose tissue about (-) $100 \mathrm{HU}$ and for soft tissues (+) $20-(+) 70$ HU (Papierska et al. 2013).

During diagnostic workup for AI, the density 
should be assessed before and $1 \mathrm{~min}$ after the administration of i.v. contrast enhancement, followed by acquisition (washout phase) 10 or $15 \mathrm{~min}$ later. The so-called imaging phenotype of a tumor, which can be "mild" or "suspicious", can be assessed on the grounds of measurements recorded in this protocol. A tumor with a mild imaging phenotype is one with low density, i.e. $\leq 10 \mathrm{HU}$. This low density means that the lipid fraction of the tumor is high, which is characteristic of lipid-rich mild adenoma (NIH 2002). In principle, an initial density $\geq 10 \mathrm{HU}$ may not require further density assessment following contrast agent administration (Papierska et al. 2013). According to the NIH Statement (2002), "an homogeneous mass with a low attenuation value (less than $10 \mathrm{HU}$ ) on CT scan is likely a benign adenoma", this is also confirmed and by other authors (Mansmann et al. 2004; Stajgis et al. 2005; Ilias et al. 2007; Pantalone et al. 2010; Zeiger et al. 2011; Papierska et al. 2013).

The calculation of so-called contrast washout coefficients expressed in percentage, is based on the density differences. An absolute coefficient is a quotient in which the difference between maximal density (during the $1^{\text {st }} \mathrm{min}$ ) and the density after 10 or 15 min, is the numerator; while the difference between the maximal value and the initial value is the denominator (result is multiplied by 100\%) (Dunnick and Korobkin 2002; Papierska et al. 2013). This parameter is used for examinations performed according to the adrenal protocol with initially planned subsequent duration of exposure (Papierska et al. 2013).

Upon the discovery of an adrenal tumor during the vascular phase on thorax CT scan without initial density value, the relative coefficient can be used. It represents the proportion between the decrease in the density from the $1^{\text {st }}$ min until the $10^{\text {th }}$ min of the examination and the density during the $1^{\text {st }} \mathrm{min}$. An absolute washout coefficient that is greater than $50 \%$ after $10 \mathrm{~min}, 60 \%$ after $15 \mathrm{~min}$ and a relative washout coefficient that is greater than $40 \%$ indicates a mild character of the lesion. This allows the diagnosis of a lipid-poor adenoma, i.e. a lesion that requires surgery only in case of the confirmed hormonal activity (ACTH-independent hypercortisolemia or primary hyperaldosteronism) (Mansmann et al. 2004; Ilias et al. 2007; Zeiger et al. 2011; Papierska et al. 2013).

Perhaps the most useful principle that can aid characterization of $\mathrm{AI}$ is evaluation of any relevant prior imaging test results. As a rule of thumb, any adrenal lesion that increases in size on serial images (usually obtained 6 months apart) can be considered malignant (Goldman et al. 1996; van Niel et al. 1999).
Caveats to this statement include some benign lesions (adenomas and myelolipomas) that, in rare cases, can increase in size very slightly over this time period. Furthermore, hemorrhage into the adrenal gland, whether traumatic or spontaneous (as in myelolipomas) will cause abrupt adrenal enlargement (Boland et al. 2008).

In addition to the above, substantial minority of pheochromocytomas have absolute or relative washout characteristics that overlap with those of lipidpoor adenomas (Patel et al. 2013), this was confirmed and by Blake et al. (2003), who have concluded that pheochromocytoma should be included in the differential diagnosis of nodules meeting washout or attenuation criteria for adrenal adenoma.

In practice, however, any increase in size is generally considered malignant until proved otherwise (Boland et al. 2008). Conversely, stability of a lesion signifies benignity (Mayo-Smith et al. 2001; Dunnick and Korobkin 2002). It is highly unusual for untreated malignant lesions to demonstrate stability on 6-month follow-up images (Young Jr 2007). According to the NIH Statement (2002), "in patients with tumors that remain stable on two imaging studies carried out at least 6 months apart and do not exhibit hormonal hypersecretion over 4 years, further follow up may not be warranted.

Furthermore, larger lesions are much more likely to be malignant (Mansmann et al. 2004; Young Jr 2007). Once an AI is larger than $4 \mathrm{~cm}$, the chance that it is malignant increases to approximately $70 \%(85 \%$ if larger than $6 \mathrm{~cm}$ ) (Dunnick and Korobkin 2002). Some authors have placed these percentages much lower, but it is unusual in clinical practice to see benign lesions larger than $4 \mathrm{~cm}$ (Szolar et al. 2005). For lesions larger than 4-5 cm, ACC should be strongly considered, particularly if the patient has no other history of malignancy (Rozenblit et al. 1996; MayoSmith et al. 2001; Dunnick and Korobkin 2002).

Both benign and malignant lesions can be heterogeneous in attenuation, particularly after the administration of intravenous contrast medium (Boland et al. 2008). Large necrotic areas in the lesion usually signify malignancy. Conversely, metastases, when detected, are often homogeneous and similar in appearance to adenomas, especially when small (Cho et al. 2013).

Song et al. (2013) have conducted a study to determine whether morphologic features of adrenal masses detected at initial contrast-enhanced MDCT can differentiate benign from malignant disease. They concluded that when an adrenal mass has malignant morphologic features, such as an irregular margin 
and heterogeneous density with a thick enhancing rim at presenting contrast-enhanced MDCT, it likely represents a malignant lesion. The remaining morphologic features, including a smooth margin and homogeneous density, being seen in both the benign and malignant disease, are not sufficient for characterization of the adrenal masses particularly in patients with a known history of malignancy.

In a Korean Study, female gender and non-contrast Hounsfield units value of $>10$ were significant risk factors for functional adrenal tumors (Mantero et al. 2000).

Magnetic resonance imaging. Of all the $\mathrm{AI}, 1 \%$ is discovered by MRI (Mantero et al. 2000). The adrenals can be delineated in nearly all the patients with MRI (Schteingart et al. 2005). Sensitivity, specificity, positive predictive value and negative predictive value for CT and MRI range from 90\% to almost 100\% according to various studies (Lee 1998; Anagnostis et al. 2009; Boland 2011; Sundin 2012; Herr et al. 2014).

The normal adrenal is of low to intermediate signal on T1- and T2-weighted imaging (Blake 2010). An MRI evaluation of the adrenals should usually consist of both T1 and T2 images (Krestin et al. 1989; Lee 1998). Dynamic serial T1W images obtained after intravenous administration of Gd-DTPA are used to show enhancement patterns of adrenal masses ( $\mathrm{Pa}-$ pierska et al. 2013).

Techniques sensitive to the presence of lipid (such as phase contrast, Dixon method, STIR (short inversion time inversion recovery sequence), and radiofrequency-selective fat suppression are most helpful in differentiating between subacute hemorrhage and fat-containing adrenal masses, both of which can appear as high signal lesions on T1-weighted spin echo images (Lee 1998).

STIR sequence is based on T1 differences of the protons. Fat has a shorter T1 value than water (Unal et al. 2015). STIR is primarily used to reveal fluid, not fat. Short T1, which corresponds to short T1W and T2W imaging, enhances tissues that have more fluid content (i.e. tumors). However, signal from protons that have short $\mathrm{T} 1$ similar to fat, such as subacute hemorrhage, gadolinium, and viscous fluid, are also adversely suppressed (Bley et al. 2010; Pokharel et al. 2013; Unal et al. 2015).

STIR is an inversion-recovery MR imaging sequence that uses a $1800 \mathrm{RF}$ pulse followed by a 900 pulse and another 1800 pulse (to produce an echo). In "traditional" inversion recovery, the time between the first 1800 pulse and the 900 pulse (termed T1) is relatively long (300-500 ms), so that T1-weighting is produced. In STIR, the T1 time is made relatively short (100-170) in order to produce fat suppression. To accomplish fat suppression, one must select the T1 value such that the 900 pulse occurs exactly when the longitudinal magnetization of fat spins is at zero, while, at the same time, some longitudinal magnetization is still present in water spins. This effectively produces both suppression (blackening) of signal from fat tissue and relative enhancement of signal from water-containing tissues. STIR also enhances differences between the water content of various tissues, because it is T1-plus T2-weighted, an additive effect that might potentially highlight disease (Paling et al. 1988; Shuman et al. 1989).

The principle of Dixon technique depends on inphase and opposed-phase imaging (Unal et al. 2015). The Dixon technique acquires two separate images with a modified spin echo pulse sequence. One is a conventional spin echo image with water and fat signals in-phase and the other is acquired with the readout gradient slightly shifted so that the water and fat signals are $180^{\circ}$ out-of-phase. Dixon showed that from these two images, a water-only image and a fatonly image could be generated. The water only image by the Dixon's technique can serve the purpose of fat suppression, an important and widely used imaging option for clinical MRI. Additionally, the availability of both the water-only and fat-only images allows direct image based water and fat quantitation ( $\mathrm{Ma}$ 2008).

Diffusion-Weighted MRI (DWI) is a technique used to detect the state of molecular translational motion of water in the tissue. In some tumors, densely packed malignant cells, causes restricted diffusion of water relative to that of normal tissue. DWI is quantified by the apparent diffusion coefficient map-apparent diffusion coefficient (ADC). Since ADC reflects primarily diffusion coefficient of extra-cellular water, $\mathrm{ADC}$ values tend to be lower for tumors compared to normal tissue. Contrary to cancer, in benign lesions, extra-cellular space volume is higher, thus ADC values are higher as well. For this reason, DWI is an important complementary tool in the evaluation of pathologic conditions in the abdomen and is increasingly used in routine imaging (Miller et al. 2010).

Miller et al. (2010) have conducted a study which aim was to evaluate the utility of ADC values for characterizing adrenal lesions and determine if DWI can distinguish lipid-rich from lipid-poor adenomas. They have concluded that unlike lesion size and percentage decrease in SI, the ADCs were not useful in distinguishing benign from malignant adrenal lesions. Lipid-poor adenomas could not be distinguished from lipid-rich adenomas and all other non- 
fatty lesions of the adrenal gland with DWI (Miller et al. 2010).

Fortunately, radiological characterization of an AI can be done with high sensitivity and specificity using well-established techniques such, CT attenuation without contrast enhancement, washout CT technique and chemical-shift MR imaging. Thus, further evaluation with diffusion-weighted MRI is not essential (Miller et al. 2010).

FDG-PET and adrenal scintigraphy. Data for FDG-PET and adrenal scintigraphy are promising (Schteingart et al. 2005). Maurea et al. (2001) have contacted a study which aim was to evaluate the role of radionuclide imaging in the characterization of non-hypersecreting adrenal masses. None of the patients, in their study, was hypersecreting or had symptoms of hypersecretion. They have concluded that "in patients with non-hypersecreting adrenal masses, radionuclide adrenal imaging, using specific radiopharmaceuticals such as nor-cholesterol, MIBG, and FDG, may provide significant functional information for tissue characterization.

Radionuclide adrenal imaging performed with specifically labelled radiopharmaceuticals that target elements of adrenal function may provide specific metabolic information for lesion characterization, thus complementing morphological imaging modalities (Maurea et al. 2001). Several radiotracers that display unique biological behavior may be used in nuclear medicine for adrenal tumor evaluation. These tracers include labeled nor-cholesterol for cortical adenomas (Francis et al. 1992), metaiodo-benzylguanidine (MIBG) (Francis et al. 1992) and hydroxyephedrine (Shulkin et al. 1992) for medullary chromaffin tissue lesions, including pheochromocytomas and ganglioneuromas, and 18F-FDG (Boland et al. 1995) and 67Ga (Truong et al. 1997) for malignant tumors.

Molecular engineering has led to the synthesis of peptides of variable forms and sizes for tumor imaging (Fischman et al. 1993). In particular, radiolabeled somatostatin analogs have been proposed in the diagnostic evaluation of several tumors (Lamberts et al. 1991). Among these, malignant adrenal masses showed significant uptake of somatostatin analog, suggesting the presence of somatostatin receptors (Maurea et al. 1996).

Professor Simone Maurea (personal communication) has proposed to select nor-cholesterol in patient with incidentalomas and no history of malignancies; as second choice, in case of no nor-cholesterol uptake by the tumor, he suggests to use MIBG; conversely, in patients with malignancies and AIs, he proposes FDG-PET imaging.
Therefore, adrenal scintigraphy is recommended for tumor diagnosis and hence, for appropriate treatment planning, particularly when CT or MRI findings are inconclusive for lesion characterization" (Maurea et al. 2001). Both radiological and scintigraphic imaging methods of the adrenal glands are necessary and therefore, should be considered complementary (Kurtaran et al. 2002).

\section{Adenoma}

It is important to emphasize that imaging cannot reliably distinguish between functioning and nonfunctioning adrenal adenomas (Mantero et al. 2000). In an Italian study (Mantero et al. 2000), the majority of the cortical adenomas were nonfunctioning $69 \%$, whereas $25 \%$ secreted cortisol in slight excess, and $6 \%$ secreted aldosterone.

Ultrasound. Adenomas are uniformly hypoechoic (relative to the fat) (Conder et al. 2009) with smooth margins and a round to oval shape, although some lesions have scalloped borders (polycyclic). Adenomas occasionally have an inhomogeneous appearance (Nurnberg et al. 2011). Because the masses are small, located deep within the abdomen, and surrounded by fat, they are often difficult to detect with U/S (Allolio 2001). Hormone-producing adrenal tumors, such as adenoma in Conn's syndrome or hyperplasia in Cushing syndrome, are generally too small to be detectable by U/S (Hofer 1999).

CT. They are usually homogeneous, round and small, and have smooth borders and well delineated margins that separate them from adjacent structures (Thompson and Young Jr 2003). Attenuation values of $<10 \mathrm{HU}$ on an unenhanced CT are practically diagnostic for adenomas (Ilias et al. 2007). A low $(<10$ $\mathrm{HU}$ ) density means that the lipid fraction of the tumor is high, which is characteristic of lipid-rich mild adenomas (Papierska et al. 2013). However, approximately $30 \%$ of adenomas are lipid poor adenomas and they are characterized by high initial density (usually up to $20 \mathrm{HU}$ and in some cases up to $30 \mathrm{HU}$ ) (Papierska et al. 2013). Density assessment following i.v. contrast administration is necessary in such cases. Moderate enhancement, followed by a rapid contrast agent washout from the tumor occurs in adenomas (Papierska et al. 2013). An absolute contrast washout of $>60 \%$ and a relative contrast washout of $>40 \%$ characterize an adenoma with a sensitivity and specificity of $98 \%$ and $92 \%$, respectively (Dunnick and Korobkin 2002; Szolar et al. 2005).

MRI. On MRI, adenomas appear homogeneous on all sequences (Ilias et al. 2007). Their contrast en- 
hancement is mild; they have low or equal signal intensity to the liver on T2-weighted images and may appear of lower signal intensity than the rest of the adrenal gland (Thompson and Young Jr 2003; Ilias et al. 2007). MRI also makes use of the lipid content of adenoma. In-phase and out-of-phase imaging demonstrates a loss of signal in a lipid-rich adenoma, on the out-of phase image compared with the corresponding in-phase imaging. A metastatic deposit does not demonstrate this loss of signal (Conder et al. 2009).

Scintigraphy. If PET/CT is performed, most malignant lesions will show avidity for 18F-FDG and most benign lesions will not (Boland 2011). In a study by Launay et al. (2015), they found that on 18F-FDG PET/CT, maximum standardized uptake values (SUV max) were significantly lower for adenomas (3.24) than for metastases (7.56) $(\mathrm{p}<0.05)$ (Launay et al. 2015).

\section{Pheochromocytoma}

Pheochromocytomas and paragangliomas are neural crest cell tumors associated with catecholamine production and assessed by a metanephrines, nor-metanephrines measurements (Mittendorf et al. 2007; Pacak and Wimalawansa 2015).

Ultrasound. Only clinically manifest pheochromocytomas are often already several centimeters in size and can be sonographically detected in $90 \%$ of cases (Hofer 1999).

Pheochromocytoma may be visible as a well-defined mass, which may be solid or cystic to variable degrees. Echogenicity will be variable (Bowerman et al. 1981). On ultrasound, pheochromocytomas have a variable appearance ranging from solid $(75 \%$ in one case series) to mixed cystic and solid to cystic (Bowerman et al. 1981).

Gray-scale ultrasound is helpful in confirming cystic-necrotic change within a pheochromocytoma. The cystic fluid may be anechoic or contain echogenic debris while posterior acoustic enhancement may be an accompanying feature (Bowerman et al. 1981). Acute hemorrhage in a pheochromocytoma may appear echogenic (Defechereux et al. 2002).

CT. Pheochromocytomas are often well-defined masses with attenuation values similar to those of muscle tissue, measuring approximately 30-40 HU (Miyake et al. 1989).

Pheochromocytoma may have attenuation values less than $10 \mathrm{HU}$ and may display more than $60 \%$ washout of contrast agents on delayed scanning. Adrenal pheochromocytomas should be included with adenomas in the differential diagnosis both for mass- es with low attenuation on unenhanced CT and for lesions exhibiting a high percentage of contrast washout (Blake et al. 2003).

Szolar et al. (2005) have conducted a retrospect study to retrospectively measure the adrenal gland attenuation and the percentage loss of adrenal gland enhancement at delayed contrast medium-enhanced CT in patients with ACC and pheochromocytoma and to compare these data with those in patients with adenomas and metastases. They have concluded that "the enhancement loss in adrenocortical carcinomas and pheochromocytoma is similar to that in adrenal metastases but significantly less than that in adrenal adenomas". The percentage change in contrast material washout is a useful adjunct to absolute CT attenuation values in differentiating adrenal adenomas from adrenocortical carcinomas and pheochromocytomas (Szolar et al. 2005).

Small neoplasms tend to be solid, whereas large lesions are often cystic or hemorrhagic (Melicow 1977). Non-secreting pheochromocytoma tends to be larger than secreting ones (Newhouse et al. 1999). Cystic degeneration may be so marked that only a thin rim of identifiable cells may remain to disclose the true nature of the lesion.

I.V. administration of non-ionic contrast material for CT is a safe practice for patients with pheochromocytoma and related tumors even without a1blocking medication (Bessell-Browne and O'Malley 2007).

MRI. Adrenal pheochromocytomas have signal intensity on MRI T1 sequences equal to or higher than that of the liver, kidney and muscle (MayoSmith et al. 2001). Pheochromocytomas have higher signal intensity than that of fat on T2W sequences. This characteristic finding is due to the hypervascularity of the tumors (Ilias et al. 2007). Another reason is that of increased water content either in the cystic or in the liquefactive necrotic tumor (Leung et al. 2013). After contrast administration, pheochromocytomas enhance avidly and have a prolonged contrast washout phase. In heterogeneous tumors, the viable areas of the tumor enhance whilst necrotic areas do not (Ilias et al. 2007).

Scintigraphy. I131 MIBG and In111 octreotide are the two radiopharmaceuticals used to evaluate for a pheochromocytoma (Mayo-Smith et al. 2001). I131 MIBG is a structural analog of norepinephrine, which is stored in neurosecretory granules of the adrenal medulla (Mayo-Smith et al. 2001). Fiebrich et al. (2009) have investigated the sensitivity of 18FDOPA PET, compared with 123I-MIBG scintigraphy and computer tomography (CT)/MRI for tumor 
localization in patients with catecholamine excess, they concluded that in order to localize tumors causing catecholamine excess, 18F-DOPA PET is superior to 123I-MIBG scintigraphy and CT/MRI (Fiebrich et al. 2009).

\section{Malignant}

Adrenals may be the site of either primary or metastatic tumors from other organs. Lung, breast, stomach, and kidney cancers, melanomas, and lymphomas most commonly metastasize to the adrenal gland (Lam and Lo 2002). While primary tumors of the adrenals are rare in adults, metastases to the adrenal glands may occur in up to $33 \%$ of patients with bronchogenic carcinoma (Forsythe et al. 1977).

In patients with a known malignancy, the likelihood of an adrenal nodule being malignant is approximately $25-36 \%$. However, in the population without a known malignancy, the prevalence is less than 0.5\% (Herrera et al. 1991; Gajraj and Young 1993; Lee et al. 1998; Song et al. 2008; Willatt et al. 2015).

On the other hand, metastatic lesions not growing for 3 years were described (Papierska et al. 2013). Furthermore, $5-25 \%$ of mild lesions grow significantly larger during 1-year observation according to various data (Papierska et al. 2013).

Adrenal carcinomas occur more commonly in the left gland than the right, and up to $10 \%$ may be bilateral. They are usually quite large at presentation, although a tumor as small as $1 \mathrm{~cm}$ has been reported (Dunnick 1990).

Ultrasound. In the presence of neoplastic involvement, however, ultrasound is of significant value in the detection of mass lesion (Anderson 1971).

Because adrenal metastases are often necrotic, they may occasionally be confused with fluid-filled masses such as adrenal cysts. This distinction can usually be made by careful observation of the internal echo content of the mass. Low-level echoes will be seen with adrenal metastases, whereas no internal echoes can be seen within an uncomplicated adrenal cyst (Hofer 1999).

Whether a suprarenal space-occupying lesion is malignant cannot be deduced from the lesion's echogenicity (Nurnberg et al. 2011). Metastasis and carcinoma are regularly hypovascularized (Nurnberg et al. 2011).

CT. When an adrenal mass has malignant morphologic features, such as an irregular margin and heterogenous density with a thick enhancing rim, at presenting contrast-enhanced CT, it likely repre- sents a malignant lesion. The remaining morphologic features, including a smooth margin and homogeneous density, can be seen in both benign and malignant disease, and are not sufficient for characterization of adrenal masses particularly in patients with a known history of malignancy (Song et al. 2008). On unenhanced CT, adrenal metastases usually have attenuation values $>10 \mathrm{HU}$ (Young Jr 2007). In patients with metastases from melanoma, attenuation values may be lower (Rajaratnam and Waugh 2005). There is central area of low density owing to necrosis. It may be calcifications and areas of hemorrhage. There is irregular peripheral enhancement following contrast (Conder et al. 2009). Large necrotic areas in a lesion usually signify malignancy. Conversely, metastases, when detected, are often homogeneous and similar in appearance to adenomas, especially when small (Boland et al. 2008).

MRI. The mix of hemorrhage and necrosis results in heterogeneous signal on both T1W and T2W imaging and irregular peripheral enhancement (Dunnick and Korobkin 2002; Conder et al. 2009). Differentiation between incidental adenomas and metastases can be conclusively achieved only when the primary neoplasm can also be imaged and displays high signal intensity on T2W mages (Reinig et al. 1986). MRI should be performed in large tumours prior to surgery to assess vascular invasion (Schteingart et al. 2005).

\section{Cysts}

Adrenal cysts are uncommon lesions, and few reports about their CT appearance can be found in the literature. Adrenal cysts show a 3:1 female predilection. Four types of cysts are recognized based on pathologic classification: endothelial, epithelial, parasitic, and posttraumatic pseudocysts (Cheema, et al. 1981).

Ultrasound. Cysts in ultrasounds show a cystic suprarenal mass. Unlike renal cysts, adrenal cysts often exhibit a thick wall. Cysts do not show Color Doppler-signals, only in border areas, which also applies to hematoma or abscesses. Pseudocysts also may have internal septa. If a soft-tissue mass like component is present, surgery may be required to exclude a neoplasm (Goldman et al. 1996; Russell et al. 2000; Dunnick and Korobkin 2002; Young Jr 2007).

CT. Most adrenal cysts, owing to their uniform and homogeneous nature, can be characterized morphologically, although some can be complex and are occasionally confused with necrotic adrenal carcinomas (Papierska et al. 2013). A small adrenal cyst with 
near-water attenuation and a thin $(\leq 3 \mathrm{~mm})$ wall is likely to be benign (Korobkin 2000). In unenhanced $\mathrm{CT}$, they demonstrate $<10 \mathrm{HU}$, in 15 -min CT cysts do not enhance (Boland et al. 2008).

MRI. They demonstrate high Signal Intensity in T2-weighted images (Boland et al. 2008).

\section{Addison disease and Cushing syndrome}

In Addison disease, there is adrenal atrophy not detectable with ultrasound; possible calcifications as evidence of prior tuberculosis (Allolio 2001).

In Cushing syndrome, in $80 \%$ of cases, there is bilateral hyperplasia due to pituitary $(75 \%)$ or paraneoplastic (5\%) ACTH overproduction; hyperplasia is usually not detectable with ultrasound (Allolio 2001).

\section{Primary aldosteronism (PA)}

Primary hyperaldosteronism has historically been underdiagnosed as a cause of hypertension, but recent reportshighlightitsubiquitousnaturewithaprevalence of $5-10 \%$ in screened hypertensive patients. Of such patients, up to $62.5 \%$ have a potentially curable adenoma as the underlying etiology (Kahn and Angle 2010).

Causes of primary aldosteronism (Moraitis and Stratakis 2011; Turcios 2015) may be 1) bilateral idiopathic hyperplasia (BIH) (60\% of cases); 2) aldosterone-producing adenoma (APA) (35\% of cases); 3 ) primary adrenal hyperplasia ( $2 \%$ of cases); 4 ) aldosterone-producing adrenocortical carcinoma $(<1 \%$ of cases); 5) familial hyperaldosteronism (FH): a) glucocorticoid-remediable aldosteronism (FH type I) $(<1 \%$ of cases), b) FH type II (APA or BIH) ( $<2 \%$ of cases); 6) Ectopic aldosterone producing adenoma or carcinoma $(<0.1 \%$ of cases $)$.

Approximately 95\% (Young 2007) of the patiets with primary hyperaldosteronism have either bilateral idiopathic hyperplasia (IHA) - optimally treated with mineralocorticoid receptor blockade - or a unilateral aldosterone-producing adenoma (APA) that may be treated with unilateral laparoscopic adrenalectomy (Young 2007; Funder et al. 2008; Young and Stanson 2009).

Adrenal venous sampling (AVS) is the criterion standard to distinguish between unilateral and bilateral adrenal disease in patients with primary aldosteronism (Young and Stanson 2009). The use of AVS to distinguish between IHA and APA was first proposed by Melby et al. (1970). Radiology together with AVS are very important in the treatment PA as only patients with lateralized adrenal hypersecretion can be cured by unilateral adrenalectomy; hence, the distinction between unilateral and bilateral aldosterone hypersecretion is the key. Ultrasounds are of no help since hormone-producing adrenal tumors, such as adenoma in Conn's syndrome, are generally too small to be detectable by U/S (Hofer 1999). According to the "Clinical Practice Guidelines" of the Endocrine Society, it is recommended that all patients with PA undergo an adrenal CT scan as the initial study in subtype testing and to exclude large masses that may represent adrenocortical carcinoma (Funder et al. 2008). Most aldosterone-producing adenomas (APA) are less than $20 \mathrm{~mm}$ in diameter (White et al. 2008). APA may be visualized as small hypodense nodules, usually $<2 \mathrm{~cm}$ in diameter on CT (Funder et al. 2008). It is mostly of an homogeneous structure. In IHA adrenal glands, they may be normal on CT or show nodular changes. Aldosterone-producing adrenal carcinomas are almost always more than 4 $\mathrm{cm}$ in diameter, but occasionally smaller, and like most adrenocortical carcinomas, have a suspicious imaging phenotype on CT (Young 2007; Funder et al. 2008). The adrenal CT lacks the overall accuracy to distinguish between unilateral and bilateral disease (Mattsson and Young 2006). On MRI, adenomas appear homogeneous on all sequences (Ilias et al. 2007). Their contrast enhancement is mild; they have low or equal signal intensity to the liver on T2weighted images and may appear of lower signal intensity than the rest of the adrenal gland (Thompson and Young 2003; Ilias et al. 2007). MRI also makes use of the lipid content of adenoma. In-phase and out-of-phase imaging demonstrates a loss of signal in a lipid-rich adenoma, on the out-of-phase image compared with the corresponding in-phase imaging. A metastatic deposit does not demonstrate this loss of signal (Conder et al. 2009). Adrenal scintigraphy with 6 $\beta$-131Iodomethyl-19-norcholesterol (NP-59), introduced in 1977, currently, it is no longer used in most centers (Funder et al. 2008). On a PET/CT scan, most commonly using 18F-fluorode oxyglucose $(18 \mathrm{~F}$ FDG PET/CT), the vast majority of adenomas do not accumulate the radiopharmaceutical. According to meta-analyses, 18F FDG PET/CT scanning generally has a high sensitivity (97\%) and specificity (91\%) in distinguishing between a malignant and benign adrenal lesion (Boland et al. 2011). In a recent study, Powlson et al. (2015) used the metomidate, as a potent ligand of CYP11B1 and CYP11B2, that can be C11H3-labelled as a PET tracer. They concluded that increasing experience with 11C-metomidate PETCT supports its use as an adjunct to AVS when this has failed, is ambiguous, or cannot be undertaken (Powlson et al. 2015). 


\section{Other rare diseases of the adrenals}

Myelolipoma. Myelolipomas are usually detected incidentally at CT, and although most are small, they can occasionally be large, hemorrhagic, or rarely, extra adrenal (Boland et al. 2008). In ultrasound, myelolipoma appears as a heterogeneous mass and it is a mix of fat and hematopoietic tissue (Conder et al. 2009). In CT, some myelolipomas are also large but are confidently recognized owing to the presence of macroscopic fat (Vella et al. 2001). Presence of fatty foci with an attenuation coefficient from less than - $30 \mathrm{HU}$ to $-100 \mathrm{HU}$ is characteristic of this mild tumor. Myelolipomas can also contain small calcifications (Cyran et al. 1996; Adusumilli and Ramchandani 2001). On MRI, there is loss of signal on fat-saturated MRI (Herr et al. 2014).

Lymphoma. Primary adrenal lymphoma is defined as malignant neoplastic proliferation of the lymphoid cells exclusively in the adrenal glands (Khurana et al. 2015). The adrenal region is a rare extra-nodal site of occurrence for lymphoma. Foci of lymphomatous infiltration have smooth borders and are hypoechoic. Differentiation is required from lymphomas in the renal or splenic hilum. If invasion by lymphoma is suspected, other nodal stations should be scanned and commonly infiltrated organs (spleen, liver) should be closely scrutinized (Birnholz 1973; Block et al. 1975; Forsythe et al. 1977; Scully et al. 1978). Imaging features include total encasement of the adrenal gland from adjacent retroperitoneal disease (making it hard to identify the adrenal gland) to smaller discrete masses or diffuse enlargement. Bilateral metastatic involvement occurs in up to 50\% of cases (Boland et al. 2008). Secondary involvement of the adrenal gland occurs in $4 \%$ of cases of nonHodgkin lymphoma at CT and $25 \%$ in post-mortem studies (Zhou et al. 2012; Herr et al. 2014).

Other very rare adrenal disease is neuroblastoma, which is more common in children, usually has large size. On CT, it demonstrates $>10 \mathrm{HU}$. More than 10 HU demonstrates also other very rare adrenal lesions, such as ganglioneuroma, hemangioma, granulamas (Boland et al. 2008).

\section{Hemorrhage}

Adrenal hemorrhage $(\mathrm{AH})$ is a rare clinical entity that may present as an AI. AH is a heterogeneous entity that occurs in the postoperative period, in the antiphospholipid-antibody syndrome, in heparinassociated thrombocytopenia, or in the setting of severe physical stress and multiorgan failure (Vella et al. 2001). Standard laboratory evaluation is not helpful in establishing the diagnosis.

In a study on AH by Vella et al. (2001), of the 141 cases of $\mathrm{AH}, 78$ were bilateral, and 63 were unilateral. A serum cortisol level of more than $18 \mu \mathrm{g} / \mathrm{dl}$ is often used to exclude adrenal insufficiency in situations of severe stress. Abdominal CT is probably the most reliable and widely available method for detecting $\mathrm{AH}$ (Vella et al. 2001). Normal findings on abdominal CT early in the clinical course do not completely rule out the presence of hemorrhage, and repeated scans are justified if clinical suspicion is high. Bedside ultrasonography may be appropriate in a critically ill immobile patient.

Ultrasound is the modality of choice for further evaluation of neonatal hematoma, and MRI is helpful for further characterization (Westra et al. 1994). Whereas tumors distort adrenal shape, the normal triangular configuration of the gland is usually preserved in cortical hemorrhage (Westra, et al. 1994). It is frequently discovered as an incidental finding at U/S performed for other reasons (Willemse et al. 1989; Kawashima et al. 1999). CT and MRI (Westra et al. 1994) are usually not required, except when the mass remains solid in appear over time or enlarges and coexisting neuroblastoma needs to be ruled out. Usually, the hemorrhage resolves completely, but it may calcify at its periphery, as seen incidentally on plain abdominal radiographs (Barzon et al. 2003).

\section{Tumor size}

In an Italian study, they found that adenomas were significantly smaller than carcinomas (3.5, range from $1-15 \mathrm{vs} .7 .5$, range from $2.6-25 \mathrm{~cm} ; \mathrm{p}<0.001$ ), and a cut-off at $4.0 \mathrm{~cm}$ had the highest sensitivity (93\%) in differentiating between benign and malignant tumor (Mantero et al. 2000). According NIH Statement (2002), they recommend that "patients with tumors greater than $6 \mathrm{~cm}$ usually are treated surgically, while those with tumors less than $4 \mathrm{~cm}$ are generally monitored. In patients with tumors between $4 \mathrm{~cm}$ and 6 $\mathrm{cm}$, criteria in addition to size should be considered in making the decision to monitor or proceed to adrenalectomy (NIH 2002).

\section{Natural history}

Concerning the natural history of AIs, the risk of malignancy over time for masses defined as benign at diagnosis is estimated at about $1 / 1000$, even though $5-25 \%$ of masses increase in size during follow-up (Barzon et al. 2003). Hyperfunction develops in about 
$1.7 \%$ of cases and the risk is higher in patients with lesions larger than $3 \mathrm{~cm}$ (Barzon et al. 2003). Cortisol hypersecretion is the most likely disorder that may ensue, and it remains subclinical in about two-thirds of cases (Bulow et al. 2006).

In a Swedish prospective study, patients with AI had a low risk of developing malignancy or hormonal hypersecretion during a short-term follow-up period (Cho et al. 2013). In a Korean Study based on their findings, initial hormonal and radiographic evaluations for AIs appear to be more important than follow-up tests because functional or malignant changes are rare (Fontana et al. 1999).

Fontana et al. (1999) evaluating the role of ultrasonography in the follow-up of AIs found that at diagnosis, U/S was not sufficiently reliable in evaluating adrenal mass characteristics. Considering the high correlation between U/S and CT size estimation, in the case of a presumably benign lesion, U/S could be considered a simple, economic, and effective method of follow-up, with CT limited to evaluating masses growing over time (CT remains mandatory at diagnosis) (Fontana et al. 1999).

According to the recommendation of the "AACE and AAES, Medical Guidelines for the Management of Adrenal Incidentalomas"; patients with AIs who do not fulfil the criteria for surgical resection need to have radiographic revaluation at 3 to 6 months and then annually for 1 to 2 years. For all adrenal tumors, hormonal evaluation should be performed at the time of diagnosis and then annually for 5 years.

\section{Conclusions}

We propose the following step-by-step approach to AI:

1. If AI was discovered by ultrasound, proceed with CT scan and biochemical tests. If AI was discovered by $\mathrm{C}, \mathrm{T}$ proceed with biochemical tests and further study of CT. These are described below.

2. We proceed at the same time with biochemical tests. These are overnight dexamethasone $(1 \mathrm{mg})$ suppression test; measurement of plasma by elevated plasma fractionated metanephrines or elevated 24 h urinary fractionated metanephrines (Mittendorf et al. 2007). If hypertension present, proceed to measurement of the plasma aldosterone concentration and plasma renin activity (Young Jr 2007).

3 . If positive, proceed to confirmation of autonomous secretion of cortisol, aldosterone, or catecholamines to avoid false positive results (Young Jr 2007) and if these are also positive, consider surgery. If there is lack of autonomous secretion of cortisol, aldosterone or catecholamines or negative results, then proceed with imaging phenotype (Young Jr 2007).

4. A) If less than $4 \mathrm{~cm}$ and if attenuation values of $<10 \mathrm{HU}$ on an unenhanced CT, this is practically diagnostic for adenomas (Ilias et al. 2007). In addition to these, and if it has benign characteristics such as homogeneous, round and small, has smooth borders and well delineated margins that separate them from adjacent structures (Thompson and Young Jr 2003), then we can safely diagnose an adenoma. B) Repeating imaging at 6, 12, and 24 months and repeating hormonal testing annually for 4 years (Young Jr 2007).

5. If size $>4 \mathrm{~cm}$ or $\mathrm{HU}>10$ or non-benign imaging characteristics of the tumor, consider surgery.

6. If during follow up either growth $\geq 1 \mathrm{~cm}$ or autonomous hormonal secretion, then consider surgery.

7. If HU as low as -20 to -100 diagnose myelolipoma and proceed as $4 \mathrm{~B}$ above.

8. If the unenhanced CT is more than $10 \mathrm{HU}$ and in terms of the tumor nature (adenoma or "nonadenoma”), primary localization (e.g. liver hilar tumor, pancreatic tumors), and infiltration of the surrounding tissues then we proceed with examination with contrast medium administration (washout assessment) (Bednarczuk et al. 2016). In comparison to unenhanced CT, based on this examination it is possible to assess the absolute and relative washout values features of the surrounding tissues infiltration, as well as the presence of liver metastases (Bednarczuk et al. 2016).

9. An absolute contrast washout of $>60 \%$ and a relative contrast washout of $>40 \%$ characterize an adenoma with a sensitivity and specificity of 98 and 92\% respectively (Dunnick and Korobkin 2002; Szolar et al. 2005).

10. If washout $<50 \%$ then there is a non adenoma lesion (Bednarczuk et al. 2016).

11. Suspicion for carcinomas increases, if the attenuation on unenhanced studies is higher than $10 \mathrm{HU}$ (Ilias et al. 2007; Young Jr 2007). On contrast-enhanced studies, carcinomas enhance avidly due to their vascularity. The pattern of enhancement can be homogeneous, unless there is central necrosis (Dunnick and Korobkin 2002; Lockhart et al. 2002; Ilias et al. 2007; Young Jr 2007). The relative percentage washout of carcinomas is $<40 \%$ (Slattery et al. 2006).

12. If either steps 10 or 11 above then consider either A or B below: A) Fine-needle aspiration biopsy if metastatic disease or infection suspected, or 
surgery or close follow-up (e.g., repeating imaging at 3 months). Before fine-needle examination, pheochromocytoma must be excluded. B) Repeating imaging at 6, 12, and 24 months. Repeating hormonal testing annually for 4 years. Surgery if mass is $>4 \mathrm{~cm}$ in diameter (Young Jr 2007).

13. If AI was discovered by MRI, then MRI can also be used to diagnose lipid rich adrenal adenomas using the dual gradient echo sequence (Willatt et al. 2015). In the case that AI is discovered by MRI, also, do steps 2, 3 above.

14. If an adrenal nodule loses signal on opposed imaging in comparison with in-phase imaging, then it can be declared an adenoma (Fujiyoshi et al. 2003; Willatt et al. 2015). More often than not, this is seen with the naked eye. However, for cases that are more equivocal, a threshold of $16.5 \%$ signal loss can be used (Caoili et al. 2000; Willatt et al. 2015). This is known as the signal intensity index.

15. Chemical shift MRI (CS-MRI) is more sensitive than unenhanced CT for intracytoplasmic lipid content and can diagnose many of the nodules which demonstrate $\mathrm{HU}$ of between 10 and 30 as lipid rich adenomas (Haider et al. 2004; Willatt et al. 2015).
16. The pheochromocytomas have very high signal intensity on T2-weighted (T2W) images, higher than adenoma or metastasis, and usually iso- or hypointense on T1-weighted imaging. Strong enhancement, which may be heterogeneous depending on the degree of cystic change (Conder et al. 2009).

17. In adrenocortical carcinoma, the mix of hemorrhage and necrosis results in heterogeneous signal on both T1W and T2W imaging and irregular peripheral enhancement (Conder et al. 2009).

18. MRI should be performed in large tumors prior to surgery to assess vascular invasion.

19. If there is suspicion for pheochromocytoma, and CT or MRI are not conclusive, you may consider either I131 MIBG or In111 octreotide (MayoSmith et al. 2001).

20. If there is problem in localization of a pheochromocytoma then 18F-DOPA PET is superior to 123I-MIBG scintigraphy and CT/MRI (Fiebrich et al. 2009).

\section{Acknowledgement}

This research did not receive any specific grant from any funding agency in the public, commercial or not-for-profit sector.

\section{References}

Abrams HL, Siegelman SS, Adams DF, Sanders R, Finberg HJ, Hessel SJ, McNeil BJ. Computed tomography versus ultrasound of the adrenal gland: a prospective study. Radiology 143, 121-128, 1982.

Adusumilli S, Ramchandani P. Adrenal myelolipoma. eMedicine - Radiology online: www.emedicine.com/radio/ topic18.htm

Allolio B. Adrenal incidentalomas. In: Contemporary Endocrinology: Adrenal Disorders (Eds. Margioriss AN, Chrousos GP), pp. 249-261, Springer-Science+Business Media, New York, 2001.

Anagnostis P, Karagiannis A, Tziomalos K, Kakafika AI, Athyros VG, Mikhailidis DP. Adrenal incidentaloma: a diagnostic challenge. Hormones (Athens) 8, 163-184, 2009.

Anderson WAD. In Pathology. Vol. I. Ed. 6. The C. V. Mosby Co., St. Louis; 819-820, 1971.

Angeli A, Terzolo M. Adrenal incidentaloma--a modern disease with old complications. The J Clin Endocrinol Met 87, 4869, 2002.

Barzon L, Sonino N, Fallo F, Palu G, Boscaro M. Prevalence and natural history of adrenal incidentalomas. Eur J Endocrinol 149, 273-285, 2003.

Bednarczuk T, Bolanowski M, Sworczak K, Gornicka B, Cieszanowski A, Otto M, Ambroziak U, Pachucki J, Kubicka E, Babinska A, Koperski L, Januszewicz A, Prejbisz A, Gorska M, Jarzab B, Hubalewska-Dydejczyk A, Glinicki P, Ruchala M, Kasperlik-Zaluska A. Adrenal incidentaloma in adults-management recommendations by the Polish Society of Endocrinology. Endokrynol Pol 67, 234-258, 2016.

Bessell-Browne R, O’Malley ME. CT of pheochromocytoma and paraganglioma: risk of adverse events with i.v. administration of nonionic contrast material. ARJ Am J Roentgenol 188, 970-974, 2007.

Birnholz JC. Ultrasound imaging of adrenal mass lesions. Radiology 109, 163-166, 1973.

Blake MA, KrishnamoorthySK, Boland GW, Sweeney AT, Pitman MB, Harisinghani M, Mueller PR, Hahn PF. Low-density pheochromocytoma on CT: a mimicker of adrenal adenoma. AJR Am J Roentgenol 181, 1663-1668, 2003. 
Blake MA, Cronin CG, Boland GW. Adrenal imaging. AJR Am J Roentgenol 194, 1450-1460, 2010.

Bley TA, Wieben O, François CJ, Brittain JH, Reeder SB. Fat and water magnetic resonance imaging. J Magn Reson Imaging 31, 4-18, 2010.

Block MB, Roberts JP, Kadair RG, Seyfer AE, Hull SF, Nofeldt FD. Multiple endocrine adenomatosis type IIb. Diagnosis and treatment. JAMA 234, 710-714, 1975.

Boland GW, Goldberg MA, Lee MJ, Mayo-Smith WW, Dixon J, McNicholas MM, Mueller PR. Indeterminate adrenal mass in patients with cancer: evaluation at PET with 2-[F-18]-fluoro-2-deoxy-D-glucose. Radiology 194, 131-134, 1995.

Boland GW, Lee M, Gazelle GS, Halpern EF, McNicholas MM, Mueller PR. Characterization of adrenal masses using unenhanced CT: an analysis of the CT literature. AJR Am J Roentgenol 171, 201-204, 1998.

Boland GW, Blake MA, Hahn PF, Mayo-Smith WW. Incidental adrenal lesions: principles, techniques, and algorithms for imaging characterization. Radiology 249, 756-775, 2008.

Boland GW. Adrenal imaging: why, when, what, and how? Part 3. The algorithmic approach to definitive characterization of the adrenal incidentaloma. AJR Am J Roentgenol 196, W109-W111, 2011.

Boland GW, Dwamena BA, Jagtiani Sangwaiya M, Goehler AG, Blake MA, Hahn PF, Scott JA, Kalra MK. Characterization of adrenal masses by using FDG PET: a systematic review and meta-analysis of diagnostic test performance. Radiology 259, 117-126, 2011.

Bowerman RA, Silver TM, Jaffe MH, Stuck KJ, Hinerman DL. Sonography of adrenal pheochromocytomas. AJR Am J Roentgenol 137, 1227-1231, 1981.

Bulow B, Jansson S, Juhlin C, Steen L, Thoren M, Wahrenberg H, Valdemarsson S, Wangberg B, Ahren B. Adrenal incidentaloma - follow-up results from a Swedish prospective study. Eur J Endocrinol 154, 419-423, 2006.

Caoili EM, Korobkin M, Francis IR, Cohan RH, Dunnick NR. Delayed enhanced CT of lipid-poor adrenal adenomas. AJR Am J Roentgenol 175, 1411-1415, 2000.

Cheema P, Cartagena R, Staubitz W. Adrenal cysts: diagnosis and treatment. J Urol 126, 396-399, 1981.

Chidiac RM, Aron DC. Incidentalomas: a disease of modern technology. Endocrinol Metab Clin North Am 26, 233-253, 1997.

Cho YY, Suh S, Joung JY, Jeong H, Je D, Yoo H, Park TK, Min YK, Kim KW, Kim JH. Clinical characteristics and follow-up of Korean patients with adrenal incidentalomas. Korean J Int Med 28, 557-5564, 2013.

Conder G, Rendle J, Kidd S, Misra RR. A-Z of Abdominal Radiology. Cambridge University Press, Cambridge, UK, 2009. www.cambridge.org/9780521700146

Cyran KM, Kenney PJ, Memel DS, Yacoub I. Adrenal myelolipoma. AJR Am J Roentgenol 166, 395-400, 1996.

Defechereux T, Degauque C, Hamoir E, Lamberty G, Preud'homme L, Meurisse M. [Discordance between actual and radiologically estimated size of an incidentaloma. Delay in questions regarding operative decision-making criteria.] Ann Chir 127, 126-129, 2002.

Dobbie J. Adrenocortical nodular hyperplasia: the ageing adrenal. J Pathol 99, 1-18, 1969.

Dunnick N. Hanson lecture. Adrenal imaging: current status. AJR Am J Roentgenol 154, 927-936, 1990.

Dunnick NR, Korobkin M. Imaging of adrenal incidentalomas: current status. AJR Am J Roentgenol 179, 559-568, 2002.

Eghrari M, McLoughlin MJ, Rosen IE, St Louis EL, Wilson SR, Yeung HP. The role of computed tomography in assessment of tumoral pathology of the adrenal glands. J Comput Assist Tomogr 4, 71-77, 1980.

Fiebrich HB, Brouwers AH, Kerstens MN, Pijl ME, Kema IP, de Jong JR, Jager PL, Elsinga PH, Dierckx RA, van der Wal JE, Sluiter WJ, de Vries EG, Links TP. 6-[F-18]Fluoro-L-dihydroxyphenylalanine positron emission tomography is superior to conventional imaging with 123I-metaiodobenzylguanidine scintigraphy, computer tomography, and magnetic resonance imaging in localizing tumors causing catecholamine excess. J Clin Endocrinol Metab 94, 3922-3930, 2009.

Fischman AJ, Babich B, Strauss HW. A ticket to ride: peptide radiopharmaceuticals. J Nucl Med 34, 2253-2253, 1993.

Fontana D, Porpiglia F, Destefanis P, Fiori C, Alì A, Terzolo M, Osella G, Angeli A. What is the role of ultrasonography in the follow-up of adrenal incidentalomas? The Gruppo Piemontese Incidentalomi Surrenalici. Urology $54,612-616,1999$.

Forsythe JR, Gosink BB, Leopold GR. Ultrasound in the evaluation of adrenal metastases. J Clin Ultrasound 5, 31-34, 1977.

FrancisIR, Gross MD, Shapiro B, KorobkinM, QuintLE.Integratedimagingofadrenaldisease. Radiology 184, 1-13, 1992.

Friedrich-Rust M, Schneider G, Bohle RM, Herrmann E, Sarrazin C, Zeuzem S, Bojunga J. Contrast-enhanced sonography of adrenal masses: differentiation of adenomas and nonadenomatous lesions. AJR Am J Roentgenol 191, 1852-1860, 2008. 
Fujiyoshi F, Nakajo M, Fukukura Y, Tsuchimochi S. Characterization of adrenal tumors by chemical shift fast lowangle shot MR imaging: comparison of four methods of quantitative evaluation. AJR Am J Roentgenol 180, 1649-1657, 2003.

Funder JW, Carey RM, Fardella C, Gomez-Sanchez CE, Mantero F, Stowasser M, Young WF Jr, Montori VM; Endocrine Society. Case detection, diagnosis, and treatment of patients with primary aldosteronism: an endocrine society clinical practice guideline. J Clin Endocrinol Met 93, 3266-3281, 2008.

Gajraj H, Young AE. Adrenal incidentaloma. Br J Surg 80, 422-426, 1993.

Ghiatas A, Chopra S, Schnitker JB. Is sonographic flow imaging useful in the differential diagnosis of adrenal masses? Br J Radiol 69, 1005-1008, 1996.

Goldman HB, Howard RC, Patterson AL. Spontaneous retroperitoneal hemorrhage from a giant adrenal myelolipoma. J Urol 155, 639, 1996.

Grumbach MM, Biller BM, Braunstein GD, Campbell KK, Carney JA, Godley PA, Harris EL, Lee JK, Oertel YC, Posner MC, Schlechte JA, Wieand HS. Management of the clinically inapparent adrenal mass ("incidentalomas"). Ann Int Med 138, 424-429, 2003.

Haider MA, Ghai S, Jhaveri K, Lockwood G. Chemical shift MR imaging of hyperattenuating (>10 HU) adrenal masses: does it still have a role? Radiology 231, 711-716, 2004.

Herr K, Muglia VF, Koff WJ, Westphalen AC. Imaging of the adrenal gland lesions. Radiol Bras 47, 228-39, 2014.

Herrera M, Grant C, van Heerden JA, Sheedy PF, Ilstrup DM. Incidentally discovered adrenal tumors: an institutional perspective. Surgery 110, 1014-1021, 1991.

Hofer M. Kidneys and Adrenal Glands. Ultrasound Teaching Manual Hofer, Matthias, Thieme, 37-50, 1999.

Hornsby PJ. Aging of the human adrenal cortex. Ageing Res Rev 1, 229-242, 2002.

Ilias I, Sahdev A, Reznek RH, Grossman AB, Pacak K. The optimal imaging of adrenal tumours: a comparison of different methods. Endocr Relat Cancer 14, 587-599, 2007.

Jain SM. Adrenal incidentaloma: A puzzle for clinician. Indian J Endocrinol Metab 17, S59-S63, 2013.

Kahn SL, Angle JF. Adrenal vein sampling. Tech Vasc Interv Radiol 13, 110-125, 2010.

Kanagarajah P, Ayyathurai R, Manoharan M, Narayanan G, Kava BR. Current concepts in the management of adrenal incidentalomas. Urol Ann 4, 137-144, 2012.

Karstaedt N, Sagel SS, Stanley RJ, Melson GL, Levitt RG. Computed tomography of the adrenal gland. Radiology 129, 723-730, 1978.

Kasperlik-Zaluska AA, Slowinska-Srzednicka J, Rosłonowska E, Kochman M, Jeske W, Otto M, Cichocki A, Slapa RZ, Zgliczynski W. Bilateral, incidentally found adrenal tumours-results of observation of 1,790 patients registered at a single endocrinological centre. Endokrynol Pol 61, 69-73, 2010.

Kawashima A, Sandler CM, Ernst RD, Takahashi N, Roubidoux MA, Goldman SM, Fishman EK, Dunnick NR. Imaging of nontraumatic hemorrhage of the adrenal gland. Radiographics 19, 949-963, 1999.

Khurana A, Kaur P, Chauhan AK, Kataria SP, Bansal N. Primary non Hodgkin's lymphoma of left adrenal gland-“A rare presentation. J Clin Diagn Res 9, XD01-XD03, 2015

Kim J, Bae KH, Choi YK, Jeong JY, Park KG, Kim JG, Lee IK. Clinical characteristics for 348 patients with adrenal incidentaloma. Endocrinol Metab 28, 20-25, 2013.

Korobkin M. CT Characterization of adrenal masses: the time has come. Radiology 217, 629-632, 2000.

Korobkin M, White E, Kressel HY, Moss AA, Montagne JP. Computed tomography in the diagnosis of adrenal disease. AJR Am J Roentgenol 132, 231-238, 1979.

Krestin GP, Steinbrich W, Friedmann G. Adrenal masses: evaluation with fast gradient-echo MR imaging and GdDTPA-enhanced dynamic studies. Radiology 171, 675-680, 1989.

Kurtaran A, Traub T, Shapiro B. Scintigraphic imaging of the adrenal glands. Eur J Radiol 41, 123-130, 2002.

Lam K, Lo C. Metastatic tumours of the adrenal glands: a 30-year experience in a teaching hospital. Clin Endocrinol 56, 95-101, 2002.

Lamberts SW, Krenning EP, Reubi JC. The role of somatostatin and its analogs in the diagnosis and treatment of tumors. Endocr Rev 12, 450-482, 1991.

Launay N, Silvera S, Tenenbaum F, Groussin L, Tissier F, Audureau E, Vignaux O, Dousset B, Bertagna X, Legmann P. Value of 18-F-FDG PET/CT and CT in the diagnosis of indeterminate adrenal masses. Int J Endocrinol 2015, 213875, 2015.

Lee JE, Evans DB, Hickey RC, Sherman SI, Gagel RF, Abbruzzese MC, Abbruzzese JL. Unknown primary cancer presenting as an adrenal mass: frequency and implications for diagnostic evaluation of adrenal incidentalomas. Surgery 124, 1115-1122, 1998. 
Lee JK, Sagel SS, Stanley RJ, Heiken JP. Computed body tomography with MRI correlation. Lippincott Williams \& Wilkins, 1998.

Leung K, Stamm M, et al. Pheochromocytoma: the range of appearances on ultrasound, CT, MRI, and functional imaging. Am J Roentgenol 200, 370-378, 2013.

Linos DA. Adrenal incidentaloma (adrenaloma). Hormones (Athens) 2, 12-21, 2003.

Lockhart ME, Smith JK, Kenney PJ. Imaging of adrenal masses. Eur J Radiol 41, 95-112, 2002.

Ma J. Dixon techniques for water and fat imaging. J Magn Reson Imaging 28, 543-558, 2008.

Mansmann G, Lau J, Balk E, Rothberg M, Miyachi Y, Bornstein SR. The clinically inapparent adrenal mass: update in diagnosis and management. Endocr Rev 25, 309-340, 2004.

Mantero F, Terzolo M, Arnaldi G, Osella G, Masini AM, Alì A, Giovagnetti M, Opocher G, Angeli A. A survey on adrenal incidentaloma in Italy. Study Group on Adrenal Tumors of the Italian Society of Endocrinology. J Clin Endocrinol Metab 85, 637-644, 2000.

Mattsson C, Young WF. Primary aldosteronism: diagnostic and treatment strategies. Nat Clin Pract Nephrol 2, 198 $208,2006$.

Maurea S, Klain M, Mainolfi C, Ziviello M, Salvatore M. The diagnostic role of radionuclide imaging in evaluation of patients with nonhypersecreting adrenal masses. J Nucl Med 42, 884-892, 2001.

Maurea S, Lastoria S, Caraco C, Klain M, Varrella P, Acampa W, Muto P, Salvatore M. The role of radiolabeled somatostatin analogs in adrenal imaging. Nucl Med Biol 23, 677-680, 1996.

Mayo-Smith WW, Boland GW, Noto RB, Lee MJ. State-of-the-art adrenal imaging. Radiographics 21, 995-1012, 2001.

Melby JC, Spark RF, Dale SL, Egdahl RH, Kahn PC. Diagnosis and localization of aldosterone-producing adenomas by adrenal-vein catheterization. Prog Clin Cancer 4, 175-184, 1970.

Melicow MM. One hundred cases of pheochromocytoma (107 tumors) at the Columbian-Presbyterian medical center, 1926-1976. A clinicopathological analysis. Cancer 40, 1987-2004, 1977.

Mengozzi G, Rossato D, Bertello C, Garrone C, Milan A, Pagni R, Veglio F, Mulatero P. Rapid cortisol assay during adrenal vein sampling in patients with primary aldosteronism. Clin Chem 53, 1968-1971, 2007.

Miller FH, Wang Y, McCarthy RJ, Yaghmai V, Merrick L, Larson A, Berggruen S, Casalino DD, Nikolaidis P. Utility of diffusion-weighted MRI in characterization of adrenal lesions. AJR Am J Roentgenol 194, W179-W185, 2010.

Mittendorf EA, Evans DB, Lee JE, Perrier ND. Pheochromocytoma: advances in genetics, diagnosis, localization, and treatment. Hematol/Oncol Clin North Am 21, 509-525, 2007.

Miyake H, Maeda H, Tashiro M, Suzuki K, Nagatomo H, Aikawa H, Ashizawa A, Iechika S, Moriuchi A. CT of adrenal tumors: frequency and clinical significance of low-attenuation lesions. AJR Am J Roentgenol 152, 1005-1007, 1989.

Montagne J, Kressel H, Korobkin M, Moss AA. Computed tomography of the normal adrenal glands. AJR Am J Roentgenol 130, 963-966, 1978.

Moraitis A, Stratakis C. Adrenocortical causes of hypertension. Int J Hypertens 2011, 624691, 2011.

Newhouse JH, Heffess CS, Wagner BJ, Imray TJ, Adair CF, Davidson AJ. Large degenerated adrenal adenomas: radiologic-pathologic correlation. Radiology 210, 385-391, 1999.

NIH Consens State Sci Statements. NIH state-of-the-science statement on management of the clinically inapparent adrenal mass ("incidentaloma"). NIH Consens State Sci Statements 19, 1-25, 2002.

Nurnberg D Szebeni A, Zatura F. Ultrasound of the adrenal glands. In: EFSUMB - European Course Book (Ed. Dietrich ChF), pp. 1-31, 2011.

Pacak K, Wimalawansa SJ. Pheochromocytoma and paraganglioma. Endocr Pract 21, 406-412, 2015.

Paling MR, Abbitt PL, Mugler JP, Brookeman JR. Liver metastases: optimization of MR imaging pulse sequences at 1.0 T. Radiology 167, 695-699, 1988.

Pantalone KM, Gopan T, Remer EM, Faiman C, Ioachimescu AG, Levin HS, Siperstein A, Berber E, Shepardson LB, Bravo EL, Hamrahian AH. Change in adrenal mass size as a predictor of a malignant tumor. Endocr Pract 16, 577-587, 2010.

Papierska L, Cichocki A, Sankowski AJ, Cwikła JB. Adrenal incidentaloma imaging - the first steps in therapeutic management. Polish J Radiol 78, 47-55, 2013.

Pasternak JD, Seib CD, Seiser N, Tyrell JB, Liu C, Cisco RM, Gosnell JE, Shen WT, Suh I, Duh QY. Differences between bilateral adrenal incidentalomas and unilateral lesions. JAMA Surg 150, 974-978, 2015.

Patel J, Davenport MS, Cohan RH, Caoili EM. Can established CT attenuation and washout criteria for adrenal adenoma accurately exclude pheochromocytoma? AJR Am J Roentgenol 201, 122-127, 2013. 
Paterson F, Theodoraki A, Amajuoyi A, Bouloux PM, Maclachlan J, Khoo B. Radiology reporting of adrenal incidentalomas - who requires further testing? Clin Med (Lond) 14, 16-21, 2014.

Pokharel SS, Macura KJ, Kamel IR, Zaheer A. Current MR imaging lipid detection techniques for diagnosis of lesions in the abdomen and pelvis. Radiographics 33, 681-702, 2013.

Popescu A, Saftoiu A. Can elastography replace fine needle aspiration? Endosc Ultrasound 3, 109-117, 2014.

Powlson AS, Gurnell M, Brown MJ. Nuclear imaging in the diagnosis of primary aldosteronism. Curr Opin Endocrinol Diabetes Obes 22, 150-156, 2015.

Rajaratnam A, Waugh J. Adrenal metastases of malignant melanoma: characteristic computed tomography appearances. Australas Radiol 49, 325-329, 2005.

Reinig JW, Doppman J, Dwyer AJ, Frank J. MRI of indeterminate adrenal masses. AJR Am J Roentgenol 147, 493496, 1986.

Rossi GP, Ganzaroli C, Miotto D, De Toni R, Palumbo G, Feltrin GP, Mantero F, Pessina AC. Dynamic testing with high-dose adrenocorticotrophic hormone does not improve lateralization of aldosterone oversecretion in primary aldosteronism patients. J Hypertens 24, 371-379, 2006.

Rossi GP, Pitter G, Bernante P, Motta R, Feltrin G, Miotto D. Adrenal vein sampling for primary aldosteronism: the assessment of selectivity and lateralization of aldosterone excess baseline and after adrenocorticotropic hormone (ACTH) stimulation. J Hypertens 26, 989-997, 2008.

Rozenblit A, Morehouse HT, Amis ES Jr. Cystic adrenal lesions: CT features. Radiology 201, 541-548, 1996.

Russell C, Goodacre B, vanSonnenberg E, Orihuela E. Spontaneous rupture of adrenal myelolipoma: spiral CT appearance. Abdom Imaging 25, 431-434, 2000.

Schteingart D, Doherty G, Gauger PG, Giordano TJ, Hammer GD, Korobkin M, Worden FP. Management of patients with adrenal cancer: recommendations of an international consensus conference. Endocr Relat Cancer 12, 667-680, 2005.

Scully R, Galdabini J, McNeely BU. Case records of the Massachusetts General Hospital. Weekly clinicopathological exercises. Case 17-1978. N Engl J Med 298, 1014-1021, 1978.

Saftoiu A, Vilma P. Endoscopic ultrasound elastography - a new imaging technique for the visualization of tissue elasticity distribution. J Gastrointestin Liver Dis 15, 161, 2006.

Shulkin BL, Wieland DM, Schwaiger M, Thompson NW, Francis IR, Haka MS, Rosenspire KC, Shapiro B, Sisson JC, Kuhl DE. PET scanning with hydroxyephedrine: an approach to the localization of pheochromocytoma. J Nucl Med 33, 1125-1131, 1992.

Shuman W, Baron R, Peters MJ, Tazioli PK. Comparison of STIR and spin-echo MR imaging at $1.5 \mathrm{~T}$ in 90 lesions of the chest, liver, and pelvis. AJR Am J Roentgenol 152, 853-859, 1989.

Slattery JM, Blake MA, Kalra MK, Misdraji J, Sweeney AT, Copeland PM, Mueller PR, Boland GW. Adrenocortical carcinoma: contrast washout characteristics on CT. AJR Am J Roentgenol 187, W21-W24, 2006.

Slonina J, Nienartowicz E, Agrawal AK, Malczewska J, Moron K. The usefulness of contrast-enhanced sonography in the differential diagnostic of adrenal tumors. Endokrynol Pol 57, 230-236, 2006.

Song JH, Chaudhry FS, Mayo-Smith WW. The incidental adrenal mass on CT: prevalence of adrenal disease in 1,049 consecutive adrenal masses in patients with no known malignancy. AJR Am J Roentgenol 190, 1163-1168, 2008.

Song JH, Grand DJ, Beland MD, Chang KJ, Machan JT, Mayo-Smith WW. Morphologic features of 211 adrenal masses at initial contrast-enhanced CT: can we differentiate benign from malignant lesions using imaging features alone? AJR Am J Roentgenol 201, 1248-1253, 2013.

Stajgis M, Guzikowska-Ruszkowska I, Horst-Sikorska W. CT diagnostic imaging of adrenal adenomas. Pol J Radiol 70, 62-68, 2005.

Slapa RZ, Kasperlik-Zaluska AA, Migda B, Jakubowski WS. Shear wave elastography of adrenal masses is feasible and may help to differentiate between solid and cystic lesions - an initial report. Endokrynol Pol 65, 119-124, 2014.

Sundin A. Imaging of adrenal masses with emphasis on adrenocortical tumors. Theranostics 2, 516-22, 2012.

Szolar DH, Korobkin M, Reittner P, Berghold A, Bauernhofer T, Trummer H, Schoellnast H, Preidler KW, Samonigg H. Adrenocortical carcinomas and adrenal pheochromocytomas: mass and enhancement loss evaluation at delayed contrast-enhanced CT. Radiology 234, 479-485, 2005.

Tabuchi Y, Otsuki M, Kasayama S, Kosugi K, Hashimoto K, Yamamoto T, Tsugawa M, Mineo I, Yamada Y, Kurebayashi S, Ohashi M, Umayahara Y, Kouhara H, Nakamura T, Taki H, Matsuoka TA, Imagawa A, Funahashi T, Shimomura I. Clinical and endocrinological characteristics of adrenal incidentaloma in Osaka region, Japan. Endocr J 63, 29-35, 2016. 
Taylor K, Ramos I, Carter D, Morse SS, Snower D, Fortune K. Correlation of Doppler US tumor signals with neovascular morphologic features. Radiology 166, 57-62, 1988.

Thompson GB, Young Jr WF. Adrenal incidentaloma. Curr Opinion Oncol 15, 84-90, 2003.

Trojan J, Schwarz W, Sarrazin C, Thalhammer A, Vogl TJ, Dietrich CF. Role of ultrasonography in the detection of small adrenal masses. Ultraschall Med 23, 96-100, 2002.

Truong B, Jolles PR, Mullaney JM. Primary adrenal lymphoma: gallium scintigraphy and correlative imaging. J Nucl Med 38, 1770-1771, 1997.

Turcios, RAS. Diagnosis and management of primary aldosteronism. Rev Mex Cardiol 26, 113-117, 2015.

Udelsman R. Adrenal. Surgery, Basic Science and Clinical Evidence. J. Norton A and R. R. Bollinger, Springer, 2001.

Unal E, Karaosmanoglu A, Akata D, Ozmen MN, Karçaaltincaba M. Invisible fat on CT: making it visible by MRI. Diagn Interv Radiol 22, 133-140, 2016.

van Niel MB, Collins I, Beer MS, Broughton HB, Cheng SK, Goodacre SC, Heald A, Locker KL, MacLeod AM, Morrison D, Moyes CR, O’Connor D, Pike A, Rowley M, Russell MG, Sohal B, Stanton JA, Thomas S, Verrier H, Watt AP, Castro JL. Fluorination of 3-(3-(piperidin-1-yl) propyl) indoles and 3-(3-(piperazin-1-yl) propyl) indoles gives selective human 5-HT1D receptor ligands with improved pharmacokinetic profiles. J Med Chem 42, 2087-2104, 1999.

Vella A, Nippoldt TB, Morris JC 3rd. Adrenal hemorrhage: a 25-year experience at the Mayo Clinic. Mayo Clin Proc 6, 161-168, 2001.

Westra SJ, Zaninovic AC, Hall TR, Kangarloo H, Boechat MI. Imaging of the adrenal gland in children. Radiographics 14, 1323-1340, 1994.

White ML, Gauger PG, Doherty GM, Cho KJ, Thompson NW, Hammer GD, Miller BS. The role of radiologic studies in the evaluation and management of primary hyperaldosteronism. Surgery 144, 926-933, 2008.

Willatt J, Chong S, Ruma JA, Kuriakose J. Incidental adrenal nodules and masses: The imaging approach. Int J Endocrinol 2015, 410185, 2015.

Willemse A, Coppes M, Feldberg MA, Kramer PP, Witkamp TD. Magnetic resonance appearance of adrenal hemorrhage in a neonate. Ped Radiol 19, 210-211, 1989.

Wilms G, Baert A, Marchal G, Goddeeris P. Computed tomography of the normal adrenal glands: correlative study with autopsy specimens. J Comput Assis Tomogr 3, 467-469, 1979.

Yeh HC. Sonography of the adrenal glands: normal glands and small masses. AJR Am J Roentgenol 135, 1167-1177, 1980.

Young, WF, Stanson AW, Thompson GB, Grant CS, Farley DR, van Heerden JA. Role for adrenal venous sampling in primary aldosteronism. Surgery 136, 1227-1235, 2004.

Young Jr WF. The incidentally discovered adrenal mass. N Engl J Med 356, 601-610, 2007.

Young, WF. Primary aldosteronism: renaissance of a syndrome. Clin Endocrinol 66, 607-618, 2007.

Young, WF, Stanson AW. What are the keys to successful adrenal venous sampling (AVS) in patients with primary aldosteronism? Clin Endocrinol 70, 14-17, 2009.

Zeiger MA, Thompson GB, Duh QY, Hamrahian AH, Angelos P, Elaraj D, Fishman E, Kharlip J; American Association of Clinical Endocrinologists; American Association of Endocrine Surgeons. American Association of Clinical Endocrinologists and American Association of Endocrine Surgeons medical guidelines for the management of adrenal incidentalomas. Endocr Pract 15, Suppl. 1, 1-20, 2009.

Zeiger MA, Siegelman SS, Hamrahian AH. Medical and surgical evaluation and treatment of adrenal incidentalomas. J Clin Endocrinol Met 96, 2004-2015, 2011.

Zhou L, Peng W, Wang C, Liu X, Shen Y, Zhou K. Primary adrenal lymphoma: radiological; pathological, clinical correlation. Eur J Radiol 81, 401-405, 2012. 